\title{
Design of Intelligent Detecting System Based on PLC for Protecting Control Box of Certain Special Vehicle
}

\author{
Hu Jiwan, Fan Zhenqin, Peng Qiang, Li Jianjian \\ Unit 63981 of PLA, Wuhan, Hubei, 430000, China \\ email:hujiwan110@163.com
}

Keywords: protecting control box; PLC; intelligent detecting

\begin{abstract}
Protecting control box is an important part of the self-protection module of certain special vehicle. In the process of usage, it is difficult to find and test when the protecting control box breaks down. And when the operator makes misoperation, the vehicle can't come to self-protection and will occur catastrophe failures which will influence equipment using life. An intelligent detecting system based on PLC is promoted in this paper. It can achieve intelligent detecting for protecting control box and will improve work efficiency and reduce the risk of maintenance and misoperation.
\end{abstract}

\section{Introduction}

In the process of vehicle usage, when the operator makes misoperation, the special vehicle couldn't come to self-protection which will make structural component damage and influence equipment using life, because of the absence of detecting device for protecting control box. To improve the vehicle detecting efficiency and prevent catastrophe failures, an intelligent detecting system for protecting control box is badly needed.

\section{Basic Principle of Protecting control box}

The protecting control box is a device for certain special vehicle to prevent unnecessary damage by its protecting control mechanism. It has two main protecting functions: one is to ensure the effective protection of the tri-proof device by shutting down the aerator and ventilating device. Another one is to judge whether the $40 \mathrm{kw}$ electric generator is allowed to be engaged and prevent engagement to protect vehicle's safety when not allowed.

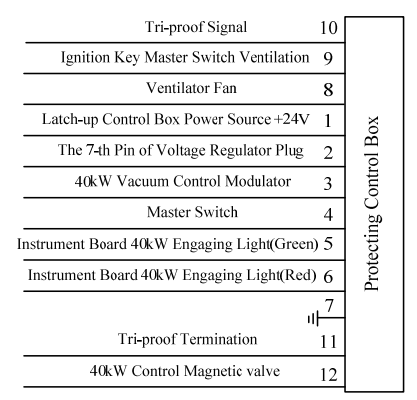

Fig. 1 Construction drawing of protecting control box

The 1-th pin: this pin connects DC $+24 \mathrm{~V}$ input, while the 7-th pin is the negative of power source which is grounded. The functions of the pins are as follows:

The 2-th pin: this pin is connected to the 7-th pin of voltage regulator Plug and transport the signal of engine speed. When this pin is power supplied, the engine works and the $40 \mathrm{~kW}$ electric generator can't be engaged.

The 3-th pin: this pin stands for the allowing turning on the $40 \mathrm{~kW}$ electric generator. The protecting control box makes the latch-up control of $40 \mathrm{~kW}$ jointing switch and judge the next action.

The 4-th pin: the $40 \mathrm{~kW}$ electric generator engagement controls the magnetic valve acting. When the $40 \mathrm{~kW}$ electric generator is allowed engaging, this pin gives a signal to engage the $40 \mathrm{~kW}$ electric 
generator.

The 5-th pin: 40kW electric generator engaging light (green).

The 6-th pin: $40 \mathrm{~kW}$ electric generator engaging light (red).

The 8-th pin: this pin connected to ventilator fan. When the Tri-proof is under non-operating condition, this pin gives a signal to make the ventilator fan work.

The 9-th pin: this pin stands for the first gear of ignition key. If the tri-proof is under non-operating condition, this pin gives a signal to connect the ventilator when the master switch of power is turned on.

The 10-th pin: the tri-proof signal.

The 11-th pin: a signal gives in at the tri-proof termination.

The 12-th pin: the turn-off switch of $40 \mathrm{~kW}$ electric generator is connected and the protecting control box receives the signal to judge whether the turn-off is allowed.

\section{The Whole Scheme Design}

Supplied by $24 \mathrm{~V}$ power source, the protecting control box receives signals outside and gives control signals out to make other actuating apparatus act by inner program and finally achieve protecting[1][2]. The intelligent detecting system for protecting control box is composed of source module, display module, input signal simulation part and output signal detecting part and so on. The block diagram is shown in figure 2.

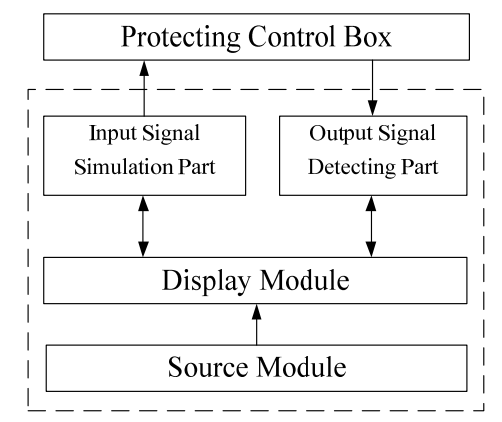

Fig. 2 The whole scheme diagram

The source module of protecting control box is used for power supply to itself and protecting control box. The display module is used for showing the input signals to protecting control box and the output return signals. The signal simulation part is used for simulating and generating return signals and sending them to active the controlling module of protecting control box. The signal detecting module is used for detecting the output control signals and ensuring the accuracy of output signals to achieve intelligent detecting of protecting control box.

\section{The Working Process}

From the construction principle of the protecting control box, The input signals contains ventilator fan working signal (the 8 -th pin), $40 \mathrm{~kW}$ electric generator engaging signal (the 6-th pin), magnetic valve closing signal (the 4 -th pin), $40 \mathrm{~kW}$ electric generator breaking indicator light signal (the 5-th pin) and magnetic valve breaking signal (the 12-th pin). The input signal contains source master switch signal (the 9-th), tri-proof termination switch signal (the 11-th pin), engine working signal (the 2-th pin) and 40kW electric generator engaging signal (the 3 -th pin).

When the source master switch is turned on, the tri-proof termination switch and the engine working switch are connected to $+24 \mathrm{~V}$ source power. When the tri-proof termination switch closes, it is needed to set light to judge whether the tri-proof termination switch is normal. Lightening means that the tri-proof termination switch is under normal condition.

When engine working switch closes, it is also needed to set light as a judgment. When the engine working light is lightening, close the $40 \mathrm{~kW}$ electric generator engaging switch, the protecting control box is out of order if the indicator light is lightening and $40 \mathrm{~kW}$ control magnetic valve acts. Because, when the engine is working, the $40 \mathrm{~kW}$ electric generator is not allowed to engagement. 
When engine working switch breaks, if the above-mentioned condition occurs and later the magnetic valve controls breaking the $40 \mathrm{~kW}$ electric generator and the whole working process has no abnormal, that means the protecting control box's function is normal, and the detecting is over. The working process of the intelligent detecting system is shown in figure below:

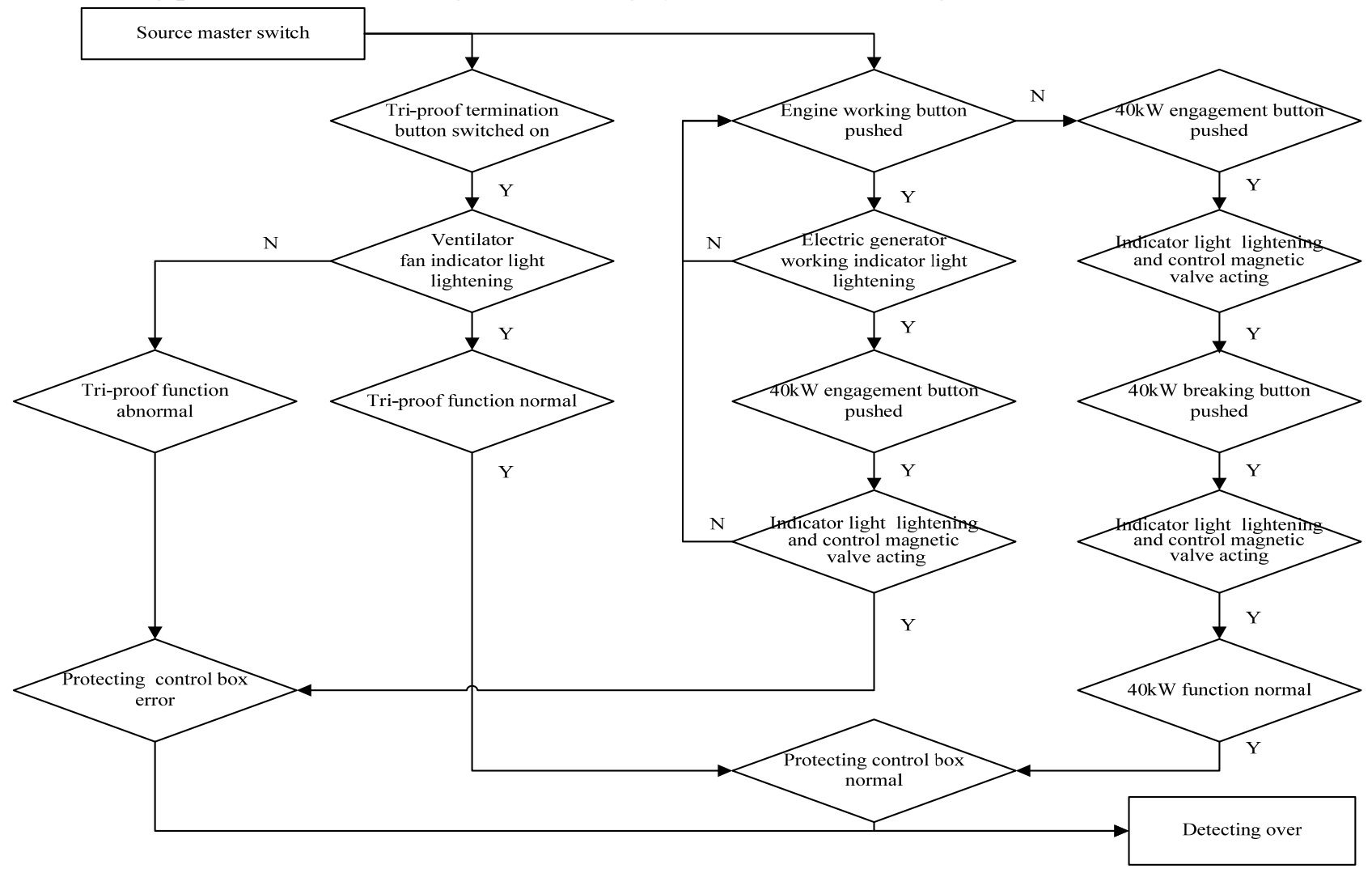

Fig.3 Intelligent detecting working flow chart

\section{System Software and Hardware Design}

Considering the maintenance need of vehicle, integrated design is taken in the detecting system to ensure miniaturization and portability. So, the case of device is portable all-aluminum suitcase which can accomplish detecting for the protecting control box whenever and wherever possible and improve maintenance efficiency greatly [3].

The left of case is integrated PLC touch screen, which is very convenient for operation. The right of case is kinds of input interface ports and control buttons of the protecting control box, including $24 \mathrm{~V}$ source input button, input signal aviation interface port and output signal aviation interface port. 


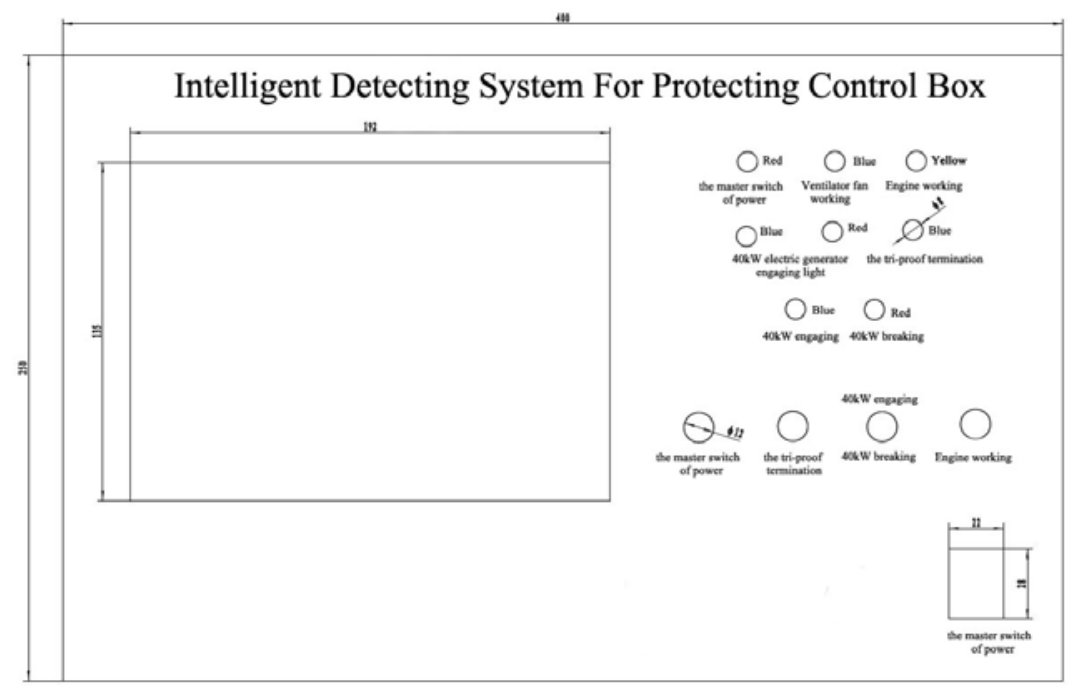

Fig.4 Case board design diagram

Considering the applicability and the cost of PLC and touch screen on the market, COOLMAY embedded integrated touch screen EX2N-70H is applied in the intelligent detecting system for protecting control box. The following picture is the physical of integrated touch screen. Name of interface port is shown in table $1[4][5]$.

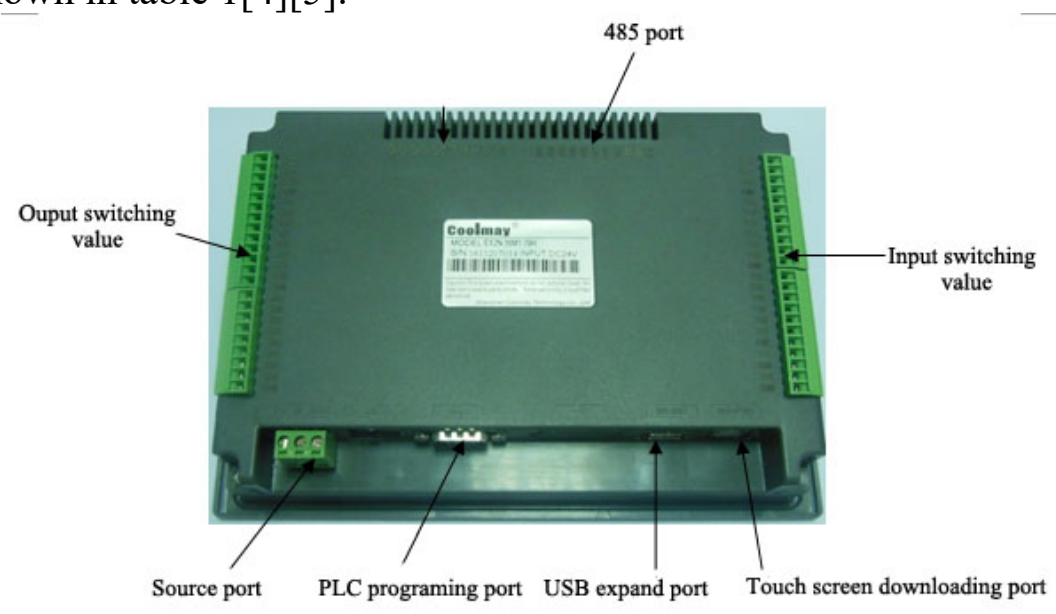

Fig.5 Integrated touch screen physical diagram

Table 1 Introduction of surface ports functions

\begin{tabular}{|l|l|}
\hline \multicolumn{1}{|c|}{ Name of ports } & \multicolumn{1}{c|}{ Introduction of functions } \\
\hline Source port & DC $+24 \mathrm{~V}$ source \\
\hline PLC programming port & Downloading PLC program by 232 line \\
\hline USB expand port & Flash disk function available \\
\hline Touch screen downloading port & $\begin{array}{l}\text { Downloading the frame of touch screen by } \\
\text { USB download cable }\end{array}$ \\
\hline Input switching value & 24 input ports maximum \\
\hline Output switching value & 18 output ports maximum \\
\hline
\end{tabular}

There is a switching state detecting source (DC 24V), which is simply connected to the switching signal of any port. In the system, when supplied by $24 \mathrm{~V}$ master source, the PLC connects touch screen input ports (the $\mathrm{X}$ port and COM port) to $24 \mathrm{~V}$ DC source by its inner arrangement circuit. Following the change of switching value, the output ports will give DC $24 \mathrm{~V}$ voltage signals to lighten the indicator lights of the touch screen. And the function state of protecting control box 
can be obtained.

Based on Mitsubishi PLC, the program construction of the system is designed by ladder diagram. And the visual operating of PLC control program is accomplished by interaction with touch screen display software.

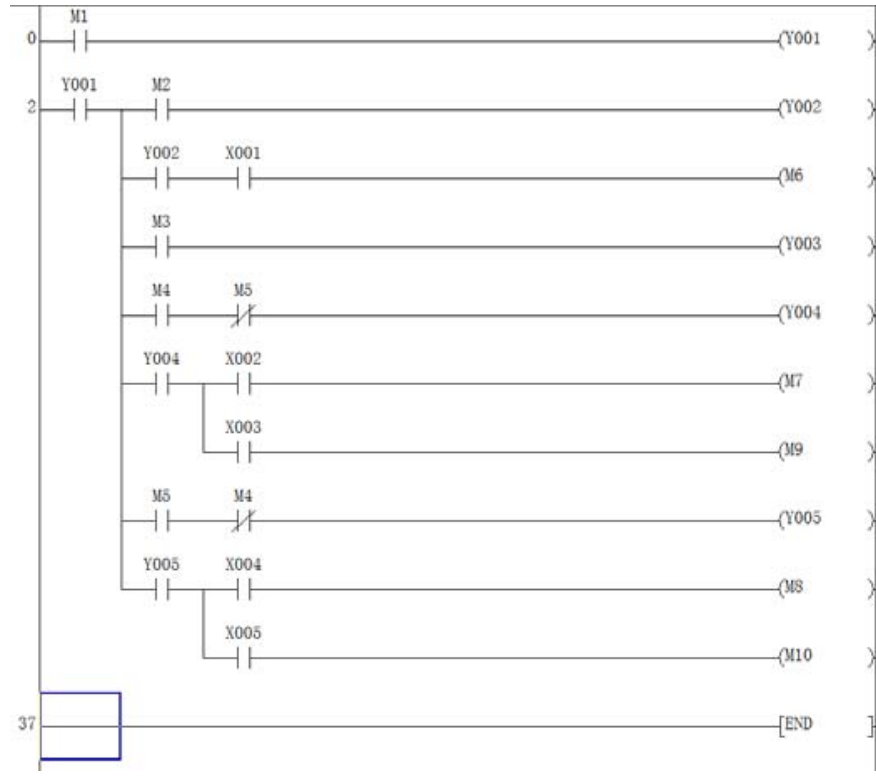

In the diagram:

Fig.6 PLC control program diagram

M1: Source master switch;

M2: Tri-proof termination switch;

M3: Engine working switch;

M4: 40kW engaging switch;

M5: 40kW breaking switch;

M6: Ventilator fan working switch;

M7: Engaging indicator light;

M8: Breaking indicator light;

M9: Magnetic valve closing;

M10: Magnetic valve breaking.

Port Y001, port Y002, port Y003, port Y004 and port Y005 give 24V voltage signals. Port X001, port $\mathrm{X} 002$, port $\mathrm{X} 003$, port $\mathrm{X} 004$ and port $\mathrm{X} 005$ are connected to COM port and receive $24 \mathrm{~V}$ voltage signals.

M5 and M4 are opposite actions and jointly accomplish self-protection by self-locking and prevent accident caused by engagement at the same time.

Combining PLC control program design, the touch screen board set five switches and four indicator lights and time synchronization update component is employed to ensure the synchronization update of intelligent detecting system.

Intelligent Detecting System For Protecting Control Box

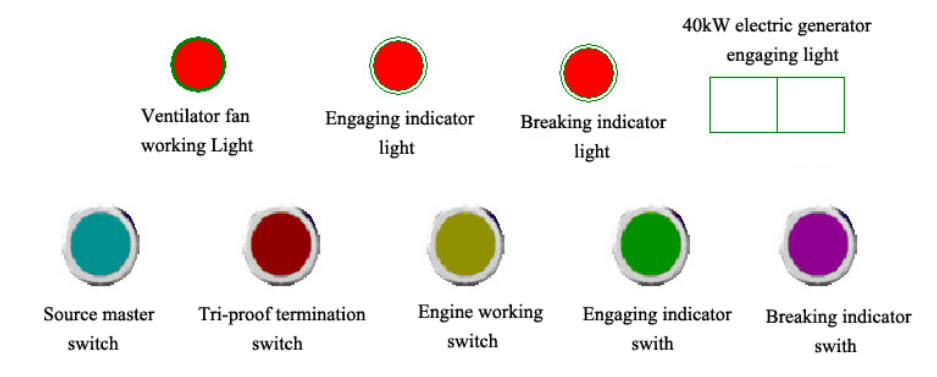

Fig.7 Touch screen display interface design 
The touch screen program is detected by off-line simulation. The source master switch is self-locking switch, which supplies DC $24 \mathrm{~V}$ source in the whole detecting process. The other four switches are keeping switch that pushed is engaging while loosen is breaking. According to the off-line simulation, indicator lights can display normally which means the touch screen self-checking function is normal.

\section{Conclusion}

After device debugging, the intelligent detecting can be accomplished by connecting protecting control box and the integrated touch screen and operation according to system detecting process. Some conclusion can be obtained: the intelligent detecting system can accomplish the function detecting for protecting control box, and when the protecting control box fails, the detecting system can return the fault information in time and locate the concrete fault point to prevent serious accident of vehicle.

\section{Reference}

[1] Chen Chanjuan, Xue Kai, Achievement to The Motion control on of the single-two axis stepper motor based on PLC [J]. Machinery Design \& Manufacture, 2009 (3) 107-108.

[2] Yang Tao, Wang Qijiang and so on, The Design of Coiling Machine Control System Based on PLC [J]. Modular Machine Tool \& Automatic, 2005 (8) 58-59.

[3] Liu Jianqin, Learn Electrical Control and PLC Technology from Zero [M]. National Denfence Industry Press, 2006.

[4] Sun Shengtao, Application Analysis of PLC In Electrical Automation Control [J]. Electronic Technology \& Software Engineering, 2013 (8) 9-12.

[5] Yu Lu, Yu Jiangze, Analysis and Application of Electrical Automation System Based on PLC [J]. Practical Electronics, 2013 (12) 21-25. 